Bernadette Bensaude Vincent

Université Paris 1 Panthéon-Sorbonne \& Institut universitaire de France

Bernadette.Bensaude-Vincent@univ-paris1.fr

\title{
Between the possible and the actual: \\ Philosophical perspectives on the design of synthetic organisms Futures 48, 2013, 23-31
}

\begin{abstract}
:
A number of research projects in synthetic biology funded by public institutions sound like science fiction: for instance DARPA Biodesign project in 2011 aimed at eliminating "the randomness of natural evolutionary advancement, and designing proteins with a $99.5 \%$ precision. How should we take such claims? Are they just fantastic visions or hype meant to impress funding agencies and the public or are they symptoms of a specific epistemic attitude?

In considering the visions of the future developed in synthetic biology the paper attempts to evaluate the research agendas of synthetic biology from philosophical perspectives. It will first characterize the ambition to re-engineer life and distinguish the visions of the future underlying the various research agendas assembled under the umbrella synthetic biology. Then addressing the question 'who actually believes in such futures?' the paper contrasts the complicit belief of ethicists and critical activists with the doubts occasionally formulated by synthetic biologists. Doubts however never generate scepticism within the synthetic biology community, which develops an epistemic opportunism. Finally the third section discusses to what extent, and in which sense, the futuristic visions of synthetic biology belong to the genre of techno-utopia. It concludes that imagined futures are integral part of the techno-epistemic culture of synthetic biology and that the tension between the possible and the actual is a criterion of distinction between the various trends that constitute synthetic biology.
\end{abstract}

Keywords: synthetic biology, economy of promises, design, engineering, futures, technoutopia

Highlights : The visions of incredible futures driving synthetic biology are part of its epistemic culture . Objections within the biosynthetic community generate epistemic opportunism instead of scepticism. Some research trends in synthetic biology are described as techno-utopia.

\section{Introduction:}

DARPA Biodesign project for fiscal year 2011 raised \$ 6 million for research aimed to "eliminate the randomness of natural evolutionary advancement primarily by advanced genetic engineering and molecular biology technologies to produce the intended biological effect" and planed to "identify and initiate strategies that would enable a new generation of regenerative cells that could ultimately be programmed to live indefinitely until needed for an injury repair or therapeutic application." The project of making immortal organisms so much challenges common sense views of life that it raised a wave of ironic comments about the 
mad scientists of the Pentagon. ${ }^{1}$ Still such fantasies continue to attract interest and million of dollars from various sources. ${ }^{2}$

Like nanotechnology synthetic biology is driven by visions of incredible futures. The prospect of design and manufacture of biological organisms triggers all sorts of fantasies: From bacteria-workers to the creation of new forms of life. Just as in nanotechnology, synthetic biology develops an "economy of promises". [1] However synthetic biology seems to go one step further. While nanotechnology has been advertised with the slogan "shaping the world atom by atom" in the 2000 US National NanoInitiative, synthetic biology opens up the more challenging perspective of designing organisms that will remake the world for us. Reengineered yeasts or bacteria will serve as pharmaceutical plants producing drugs. Synthetic algae will provide renewable fuel for our daily consumption of energy. Synthetic bacteria will decontaminate the soils polluted by chemicals and nuclear waste.

It is tempting to dismiss such promises as hype forged by the mass media. However it is not limited to popular press since it is used by scientists and policy makers as well. Scientists have their own way to justify their bold claims about the potentials of synthetic biology by the pressures from funding agencies for research aimed at useful applications. Is the concern with potential impacts of research on economy or medicine the only justification for utopic visions in today synthetic biology?

I will argue that the economy of promises developed in synthetic biology is more than a rhetorical device for the purpose of raising funds or public attention. Rather it seems that synthetic biology - like nanotechnology - did unleash imagination and enhance its role in scientific research. However synthetic biology is extremely multi-faceted and not all research programs gathered under this umbrella are promising incredible futures. Therefore in examining to what extent futuristic visions and bold claims characterize the epistemic culture of today synthetic biology, it is important to take into account the epistemic pluralism of synthetic biology. [2]

The first section of this paper considers the visions of the future outlined in the various research agendas assembled under the umbrella synthetic biology. The second section discussing the credibility of various projects in synthetic biology points to a striking contrast between the complicit belief of the critical activist community and the more sceptical views developed within the community of synthetic biologists. Finally the third section argues that a significant part of the research programs currently conducted under the umbrella synthetic biology belong to the genre of techno-utopia and uses the tension between the possible and the actual as a criterion for distinguishing the various research trends within synthetic biology.

\section{Imagined futures}

\subsection{Speech-acts}

The power of the promises of synthetic biology rests on the design of predictably functional organisms that will perform a variety of useful and desirable tasks for us. The main messages conveyed in the popular press as well as in the pages and blogs of scientific periodicals is that life and nature are no longer to be viewed as a given, as the inexorable necessity opposing resistance or constraints to all technological projects. New biological systems can be constructed and "might be harnessed to serve humanity". [3] A strong vision of life as a resource for human design is being shaped through pictures, slogans, and papers. For

\footnotetext{
${ }^{1}$ See for instance Wired on http://www.wired.com/dangerroom/2010/02/pentagon-looks-to-breed-immortalsynthetic-organisms-molecular-kill-switch-included/and DARPAS's response http://techinsider.nextgov.com/2010/02/the_misunderstood_mad_science_of_darpas_biodesign_project.php ${ }^{2}$ see for instance the call from Templeton University, http://chronicle.com/article/Intimations-of/133287/).
} 
instance, on the cover page of an issue of Nature dedicated to biodesign one could find a cartoon subtitled "Life is what we make it".[4] In taking up this formula of popular wisdom, a strong message was delivered: life-as-it-is should give way to life-by-design. The message was reinforced on the cover of an issue dedicated to genome sequencing bearing the title "Your life is in your hands". [5] The assertive mode of this cover pages echoes Rob Carlson's title Biology is Technology. [6] Such propositions can be viewed as typical "performative sentences", sentences, which do something in the world rather than describing something about it. [7]

What can be the impact of such "speech acts"? They invite researchers to action, whether they be driven by curiosity, by the desire to advance our understanding of natural life or by more practical goals with environmental or pharmaceutical applications in view. The use of this kind of language in scientific journals reveals a remarkable pragmatic turn toward action, which goes far beyond the promises of industrial applications. This proactive attitude is said to bring about powerful research tools for better understanding the conditions and dynamics of life. Constructing organisms rather than simply experimenting on them, is the road for increasing our knowledge of life in the future. Knowing through making, the cognitive strategy developed and routinely used in chemistry is applied to biology. Over the past decade the regular quotations of Richard Feynman's alleged statement that "What I cannot create, I do not understand" became a catchword and marker for creating a community.

\subsection{Variations and convergences}

As many outsiders have emphasized, synthetic biology is extremely multi-faceted and not all research programs gathered under this umbrella are promising incredible futures. [8] In fact, the emphasis on design could well be the unique link that ties together the constellation of multidisciplinary groups usually gathered under the umbrella synthetic biology, since they have quite diverse research agendas. To the question "What's in a name" [synthetic biology] the editor of an issue of Nature Biotechnology [9] did not get a uniform answer, but a consensus emerged from a dozen of answers around two key notions: engineering and design. There are striking contrasts between the Biobrick program developed around the MIT Registry of standardized bioparts, driven by the ambition of applying the principles of civil engineering to living organisms and research programs aimed at making protocells. While the latter program combines theoretical modelling and experimental construction with the view to disentangle the basic conditions required for the origin of life, the champions of the Biobrick program promise a more exciting future. The living world will become part of the industrial infrastructure and the economy will be restructured around biological manufactures assembling bioparts. For instance, in 2001 Robert Carlson envisioned 2050 in these terms:

"In fifty years, you may be reading The Economist on a leaf. The page will not look like a leaf, but it will be grown like a leaf. It will be designed for its function, and it will be alive. The leaf will be the product of intentional biological design and manufacturing." [10]

Constructing reliable artefacts that get rid of all the messiness and unpredictability of natural systems is the condition for the industrial future of biotechnology. Drew Endy claims to "make routine the engineering of synthetic biological systems that behave as expected". [11] Research programs aimed at making minimal genomes share the project of implementing desired functionalities in a chassis. However they differ from the Biobrick program as the emphasis is less on intentional design and more about demonstrating capabilities of challenging nature. Proofs of concept are celebrated as records in sports competitions. For 
instance in 2010 Craig Venter presented his synthetic bacterium Mycoplasma Mycoïdes as "the first self-replicating species we've had on the planet whose parent is a computer." More ambitious is the branch of synthetic biology often referred to as "unnatural-biology". The synthesis of new types of nucleic acids aims at generating novel forms of life that evolution could have made. It is part of a broader discipline named "universal biology", whose objective is to move beyond the circumstances of the particular origins of life on earth and to identify the general principles of life according to the universal laws of physics and chemistry. It aims at investigating, both the past, the origin of life and the principles that will shape life in the future. However this cognitive goal is intertwined with more practical expectations to design bio-devices and machines for more immediate technological or medical applications.

Underlying the project of designing unnatural forms of life is a specific vision of progress as a process of emancipation from an imperfect nature. DNA, RNA and the cell machinery are certainly robust but natural life is not optimal as they are fundamentally contingent. By changing one or two of the four bases of DNA while keeping the acceptor-donor hydrogen bonds in its structure, it is possible to build up artificial genetic systems that can support evolution. For Steve Benner, synthetic biology is a promising pathway to explore alternative forms of life that might exist in other environments. [12] In this respect, synthetic biology is a matter of interest for NASA:

Biology on Earth readily demonstrates that life is an efficient user of resources around it, turning those resources into habitats, materials and forms that perform various functions. Synthetic biology in space represents a new challenge, the challenge of designing organisms to perform reliable functions that an astronaut may one day depend on. If the promise of an engineerable biology on Earth is within reach the initiative aims to develop applications for synthetic biology in space". [13]

Benner even claim that synthetic biology overtakes nature and allows us to get rid of its imperfections. In a lecture eloquently entitled "Redesigning DNA: Fixing God's mistakes", Benner argued that:

" The structure of DNA is far from perfect because it reflects events that occurred at the origin of life and in subsequent episodes of life where constraints on the structure of biomolecules were quite different from those today, and certainly not conducive to creating a biomolecule that serves the goals of the analytic chemists, the bioengineer, or the synthetic biologists. Fortunately the theory and synthesis are both adequate to make a better genetic material". [14]

In addition, a number of synthetic biologists argue that artificial genetic codes may be needed in case of a catastrophic event that would erase life as it is from the earth. In other terms generating artificial biodiversity thanks to unnatural molecular biology is presented as a plausible response to environmental protection. [15]

\subsection{Technomimetism}

Slight differences are thus perceptible in the ambitions of the various trends of research in synthetic biology: improving on nature in the Biobrick program, challenging nature in genome engineering, emancipation from nature in unnatural biology. Nevertheless all discourses and images about synthetic biology converge towards the vision of redesigning life along technological principles, implementing the principles of rational design in natural 
systems. In stark contrast to the tradition of biomimicry, or bio-inspired chemistry, synthetic biology is promoted as an alternative strategy that could be labelled "technomimetism". Biomimetism is dismissed as a poor amateurish strategy:

"If biological engineering were aviation, it would be at the birdman stage: some observation and some understanding, but largely naive mimicry. For the field to really take flight, it needs the machinery of synthetic biology. [...] At the turn of the last century, the Wright brothers achieved manned flight not by mimicking natural systems, but by applying the principles of engineering and aerodynamics. Similarly, synthetic biology allows us to dispense with biological mimicry and design life forms uniquely tailored to our needs. In doing so, it will offer not only fundamental insights into questions of life and vitality but also the type of exquisite precision and efficiency in creating complex traits that genetic engineers could previously only dream of'. [16]

The synthetic biology community thus gradually built up a grand narrative based on a broad historical picture of technology disqualifying nature. They shape a specific vision of the future, as being in the hands of humans, that Barbara Adam named the future as fortune by contrast to the mythical and religious view of the future as fate. [17] The view of a predestined fate unveiled by prophets has been destroyed in the Enlightenment and replaced by the view of the future as an open and empty space to be colonized and controlled by humans. The future has to be made through action and planning. No longer do we need priests or prophets pretending to prepare people to accept their fate we need scientists and engineers to act upon the future.

This shift from "future presents" (predetermined) to "present futures"( as outcome of human choice and action) often implies a devaluation of nature and of life-as-it-is. The present future similarly downplays the current state of the art for the benefit of the imagined future. Many synthetic biologists (Endy and Carlson in particular) like to contrast the clumsy practices of customized genetic engineering, depicted as poor and inefficient tinkering with the clean practices of synthetic biology, based on sound engineering principles such as standardization, abstraction and decoupling. The shift towards abstraction that we observe in the vision of the future is paralleled by a shift toward abstraction in the concept of life, although life is not exactly an empty space to colonize. Rather it is a text that can be deciphered and rewritten. Decoding commands recoding and redesigning.

To sum up this section, strong visions of the future as improving nature, challenging nature or emancipating from nature, permeate synthetic biology. In spite of diverse engineering ideals and practices, all synthetic biologists seem to share the conviction that designing or redesigning organisms is making the future. At the frontier of science, they are transforming life into a major resource. The future they have in mind is a future of unrestricted economic growth and expansion of the mastery of humans over nature. In short, they revive the common modernistic views of progress, with science and technology as a driving force.

\section{Issues of credibility}

While the faith in progress is not really the dominant view in today Western societies, one may wonder who can share the visions of the future underlying synthetic biology. The extravagant promises of synthetic biology decided policy makers to bring social scientists in the field, to assess the potential societal, legal, economic and ethical impacts of synthetic biology. [18] Their bold claims prompted worries and strong reactions from a number of civil associations and NGOs. 


\subsection{Believers in alert}

Ethicists and activists seldom question the credibility of the promises made by the champions of synthetic biology. On the contrary, they often take them seriously as they try to draw the public's attention to their potential impacts on civil society and environment. For instance, a report Extreme Genetic Engineering, published by the Canadian action group on Erosion, Technology and Concentration (ETC Group) in January 2007 spread the view that unnatural organisms were already among us. [19] In their effort to alert the public and decision makers about the risks of bio-terrorism and environmental issues, they made the imagined future more present, more real. In the aftermath of Craig Venter's announcement of the design of a bacterium with synthetic genome, in May 2010, the ETC Group went even further in turning speculative futures into present futures, when they issued a short alarming note entitled Synthia is alive ... and breeding. In order to raise legitimate doubts about the potentials of synthetic genomes, they took Venter's claims and promises at face value. For instance, Jim Thomas of commented: "This is the quintessential Pandora's box moment - like the splitting of the atom or the cloning of Dolly the sheep. We will all have to deal with the fall-out from this alarming experiment."[20]

A similar perverse effect resulted from the ethical discussions about the societal aspects of synthetic biology. The list of issues - biosafety, biosecurity, biohackers, etc - resulting from the accompanying ELSI programs tends to reinforce the credibility of the promises made by synthetic biologists. [21] As pointed out by Alfred Nordmann about the ethics of nanotechnology ethicists endorse and validate an incredible future in their effort to evaluate their impacts. "This discourse violates conditions of intelligibility, squanders the scarce and valuable resource of ethical concern, and misleads by casting remote possibilities or philosophical thought experiments as foresight about likely technical developments."'[22] Instead of developing a critical assessment of the promises of synthetic biology, ethicists and activists seem to be fascinated by their visions and follow their futuristic talk.

\subsection{Objections from within}

Ironically, it is among the practitioners of synthetic biology that one can find more sceptical attitudes. The most serious doubts about the promised futures are to be found in a number of remarks coming from within the community. They are based on quite different grounds: on theoretical assumptions, on experimental aspects, and on economic considerations.

On the theoretical front, Antoine Danchin, a French geneticist working on bacterial genomes questioned the ambition of building synthetic bacteria affording permanent capabilities. His argumentation is based on the informational paradigm and the analogy between cells and computers, which drive many projects of synthetic biology. Looking more closely at this analogy, Danchin assumes that in both cases there is a separation of functions: the hardware is separated from the software in computers and the processes of gene expression separate the genome from the cell machinery. [23] However "computers do not make computers". Whereas the program replicates, the cell reproduces itself (make similar copies). Synthetic biologists tend to focus on the role of the genome and consequently overlook the role of the chassis.

"The present avatar of Synthetic Biology (SB) assumes that we know enough of what life is to allow us to construct life from scratch, or, at least, to modify existing cells and organisms so that they work as cell factories. With this view SB puts together two separate entities, a program (the conceptual extension of the genetic program) and a chassis (the conceptual extension of the living cell). Yet a rapid browsing of 
publications in the domain indicates that the vast majority of SB-related work deals with the program, not the chassis. Most investigators do as if the recipient cell would be nice enough to accommodate entirely artificial constructs and behave as expected, producing the right products, with the right yield, at the right time. Several hard constraints however make this dream difficult, if not impossible to achieve." [24]

The genome itself raises a dilemma because in its most entrenched part (paleome) the same genes have a dual function: they secure innovation and they work for the maintenance of the system. They act as information-traps and power stations at the same time. They thus combine evolution and prevention of the degradation of the functional units. Consequently synthetic organisms will either unpredictably evolve and their functional units cannot be guaranteed; or they will be ageing and require a continuous reconstruction of the functional units. The prospect of immortal cells is accordingly dismissed as unrealistic, and the promise of making sustainable microorganisms that would afford permanent functional capacities is also questioned.

Whereas Danchin's doubts proceed from broad theoretical assumptions about life, other doubts about the feasibility of some promises emerge from the practice of synthesis. For instance, Steve Benner who is one of the pioneers of synthetic biology (he synthesized DNA in the 1980s) still active in the synthesis of exotic unnatural DNAs, raise doubts about the basic assumptions underlying the Biobrick project. The foundational principles necessary for the achievement of engineering biology have been clearly formulated by Endy in a famous article: standardization (full description $\&$ characterization of bioparts); decoupling (divide a task into manageable operations) and abstraction (dealing separately with each level of complexity). [15] To Benner who has life-long experience of biochemical synthesis, making standard interchangeable parts is an ideal far from the actual practices of synthesis. Unlike the parts assembled in mechanical engineering the building blocks of synthesis inevitably interact. Their identity and behaviour is to a certain extent determined by their interactions. In thus emphasizing the gap between the engineering ideals of the Biobricks program and the principles at work in actual practice, Benner suggests that the delivery of this ambitious and attractive research program will never be up to the promises. Actually the rare successes of synthetic biology such as the biosynthesis of artemisinin - an anti-malaria drug - were not the result of rational design. In reality they were achieved through more messy and painstaking practices with trials-and-errors and workarounds. As Maureen O'Malley convincingly argues the engineering of metabolic pathways requires a lot of 'kludging' (a term made out the initials of klumsy, lame, $u$ gly, $d$ umb, but good enough) referring to quick and dirty solutions. [25] The self-image of synthetic biologists as responsible engineers relying on sound and rational principles is at odds with their actual practice of skilled and astute biochemists. The designing practices of another pioneer of synthetic biology, Michael Elowitz, could also lead to subvert the engineering principles underlying synthetic biology. Elowitz's initial efforts to design genetic circuits "from scratch" were based on the principles of decoupling and abstraction. [26]. He worked hard to build a circuit that would function as independently as possible from the underlying cellular system turned out to be unrealistic. However he realized that noise and interaction with the host cell were inevitable. [27] The basic assumption of the modularity of biological systems thus seems to be really threatened by his research over the past ten years,

The industrial and commercial future of synthetic biology has been questioned by one of its most dedicated champions, Rob Carlson. Carlson casts doubts on the economic potentials of the Registry of Standard Biobricks when he assumes that most biological parts designed by the students in iGEM competition do not work and would be useless for industrial developments because they are not well characterized. [6: 51] His most serious doubts rest on 
economic arguments. In his view, bio-economy as it is currently envisaged is not sustainable. In particular Carlson undermines the commercial future of Venter's celebrated prowess. He argues that given the amount of money invested just for the first phase of experimental assembly of a synthetic genome the cost of the next stage and the scaling up of synthetic bacteria would exceed all plausible capacities of financial investments. [6:104-105] Thus Carlson unwillingly provides the critics of synthetic biology with powerful arguments, although to him such defects are just an encouragement to go further and reach the critical mass necessary for the take-off of synthetic biology by getting rid of all patents and regulations.

\subsection{Practitioners believers?}

The three types of objections - theoretical, experimental and economic - raised by a number of practitioners of synthetic biology are clearly articulated and publicized. They could be factors of division within the community of synthetic biologists. But doubts are not presented as potential criticisms undermining the future of synthetic biology itself. Remarkably, Elowitz and his team never openly questioned the central assumptions of the Biobrick program. Instead they are developing "a new generation of synthetic circuits that integrate more closely with endogenous cellular processes". [27] It is expected that the second generation of genetic circuits will result in a deeper understanding of regulatory processes and evolution of genetic circuits. From the basic science perspective it is a remarkable gain of knowledge. However from an engineering perspective, such integrated circuits would be at odds with the strict control and predictability promised by the champions of the Biobrick program. [28] Elowitz's recent results could thus have been interpreted as a refutation of the engineering program. Instead they are presented as an invitation to move further on. Noise and interactions are supposed to be advantageous to achieve specific functions in genetic circuits, rather than undermining the ambition to improve on nature.

Here points a distinctive feature of the community of synthetic biology. Negative results never generate blame or disqualification of colleagues. They are not sceptical scientists. They ignore Robert Merton's famous "organized scepticism", one of the four pillars of the scientist' ethos. They are hard-rock optimists who spring back on all obstacles. Failures or difficulties are never seen as refutations that could threaten the promises. Objections are turned into challenges, negative results into new opportunities. The prohibiting costs of today achievements in synthetic biology are just defects, due to a science still in infancy and it is expected that the costs will exponentially decrease in the next decades. Synthetic biologists are never disappointed, never deeply disturbed in their credo. They are flexible; they are versatile, open to all opportunities.

Furthermore, there is no apparent competition between the various branches of synthetic biology. Instead of behaving as a pack of rival ambitious hounds, they run all united behind a flag in the conquest of the future. Far from dividing the community, the promises and imagined futures of plenty seem to act as the cement building a collective out of a cluster of researchers coming from various disciplines and using various tools and languages. The promises need not to be taken as real objectives. They may be just buzzwords generating an atmosphere of activity and excitement around a target. Buzzwords have a dual power: They point to the direction of an attractive and highly desirable object, acting like a magnet; at the same time they conjure up the image of a swarm of bees moving together to found a new colony, thus blurring all potential conflicts, tensions or even frictions in the group. Or to use a biblical metaphor, the imagined futures can be seen as a secular version of the mythical Promised Land. Just as the Promised Land made one people out of twelve tribes, the imagined futures create a horizon of expectations cementing a community of practitioners with different 
backgrounds and languages.

The indefectible optimism cementing the community of synthetic biologists is encouraged by the prevailing knowledge economy. ${ }^{3}$ The promises of synthetic biology rely on the assumption that investing in a specific domain of research is good for national competitiveness in a global market. New technologies such as synthetic biology seem a necessary - if not sufficient - condition to deal with pressing economic, societal and environmental issues. So strong is the power of the equation technological innovation=economic growth underlying all this techno-futuristic talk, that technological solutions are expected to all issues.

In sum, the question opening this section - 'who believes in the incredible futures of synthetic biology'? - may not be the right question. Synthetic biologists do not need to believe they just share the enthusiasm raised by the grand futuristic visions displayed on the front-covers of their favourite journals. As for activists and ethicists they might well question the basic assumptions rather than discussing the promises.

\section{Technoscientific utopia?}

The importance of futuristic visions in synthetic biology or nanotechnology raises a broader issue: to what extent utopia permeates the epistemic culture of those technosciences? Instead of comparing the promises of technosciences to a conventional definition of utopia, it seems more relevant to start from the notion of the future and display the variety its modalities. Aristotle characterized the future as contingent, but there are various distinguishable ways of being in-between the impossible and the necessary. The "potential" waiting to be actualized (the seed that will produce the flower) is not unreal in the same manner as the "possible". The possible in turn denotes either a logical possibility (no intrinsic contradiction), or a physical possibility (compatible with natural laws), or a practical possibility (feasible), or a moral possibility (permitted or acceptable).

Moreover there is no point of view of outside observer to envision the future. No privileged standpoint allows to objectively assert that the promises of synthetic biology are either unrealistic or realistic. Therefore three different perspectives - historical, epistemological and metaphysical - are displayed without claiming that no other perspectives could be adopted.

\subsection{Historical perspective}

Like many new promising technologies, synthetic biology is advertised as the Nth Industrial Revolution opening up a new era of clean and sustainable development based on the systematic exploitation of biological resources. These claims have an air of déjà $v u$. As Steven Shapin notes: "Few things are as passé as past futures" [29]. In the mid-twentieth century a world was promised where beefsteaks made out of oil would alleviate world poverty. Fifty years later the promise has switched to substitutes of oil, fuels made out of feedstock. Futuristic visions are so attractive that they blind the past.

Synthetic biologists are blind to innumerable previous attempts at making life in a test-tube, from medieval alchemy to twentieth-century dreams of engineering life. [30] Although

\footnotetext{
3 The knowledge economy initiated by the Organization for Economic Cooperation \& Development (OECD) in the 1990s and translated into a roadmap for Europe in the 2000 Lisbon Agenda is based on the pivotal role of innovation in economic development. Increasing knowledge generates capital, increases the Gross National Product more than material resources. Against the background of economic depression in Europe the mission assigned to R\&D was to increase economic competitiveness and create new jobs.
} 
synthetic biologists benefit from unprecedented technical means, their strategies are not always novel. They re-enact schemes developed by alchemists and synthetic chemists. ${ }^{4}$ Indeed one cannot conclude from past successes or failures to success or failure in the future. However planning the future without taking into account similar past experiences is not the most reliable route. The futuristic visions of today technoscientists are strikingly amnesic, so detached from the past that they are totally abstract. In particular, synthetic biology is often promoted as a source of technological fixes: biofuels meant to stop the overconsumption of fossile fuels, synthetic bacteria to repair the damages caused by chemical industries and nuclear power stations. But the concern with the damages due to the previous generations of "new technologies" does not invite reflections about the next new generations, i.e. the longterm unintended consequences of all technological innovations. To be sure, the advocates of synthetic biologists include risk assessment in their programs in the name of 'responsible innovation'. They earnestly address issues of biosafety and biosecurity in their annual conferences. Yet they only rely on technological solutions of confinement (physical, biological, evolutionary confinements), which in turn will raise new issues. Whatever the plausibility of the technical solutions for preventing the dissemination of and contamination by synthetic organisms, they never take into account past experiences, never draw lessons from the past. As the historian of technology David Edgerton argues the current "futuristic guru-talk" relies on a superficial and biased view of the history of technology. [31] Synthetic biologists only look at the past to select a few conventional standard examples (preferably taken from synthetic chemistry or aviation) detached from their contexts. [32] They ignore the complex reality of past technological achievements, how they combined innovations and old familiar techniques. They overlook the path-dependency created by technological trajectories, and their negative impact on attempts at optimization. In the light of past technologies, of synthetic biologists look like a self-fulfilling prophecy, and their capacity to plan and master the future as a utopia.

\subsection{Epistemological perspective}

Imagination strikes as a prominent feature in the epistemology of synthetic biology. In standard scientific methods, imagination is usually strictly confined and duly controlled for being a capacity generating fictions rather than facts, unrealistic scenarios rather than practical solutions. In synthetic biology and recent biotechnologies, imagination takes a more positive and important role, which is by no means in contradiction with the exercise of reason and reasoning. Imagination provides guidelines for action because it bridges the gap between the possible and the real. [33] It is precisely a reflection on the space between the possible and the real, which inspires the design of unnatural forms of life. Synthetic biologists working in this field, are engaged in a systematic exploration of the realm of the possible, and only indirectly concerned with understanding life or coming up with profitable innovations. This epistemic attitude is instantiated in Benner and Sismour's attempts at synthesizing novel forms of life, based on new types of nucleic acid or a different genetic code. [34] The modification of the standard code is not just meant to design living tools for remediating natural defects or improving on nature. Rather it seems to be driven by a concern for exploring all kinds of potentials and actualizing them. It is the coming into being of

\footnotetext{
${ }^{4}$ For instance, the minimal genome approach seeking to construct new organisms and new functionalities on the basis of the minimum equipment required for sustaining life resembles the strategy used by nineteenth-century chemists to branch chemical functions on the benzene ring for making all sorts of aromatic compounds. It also evokes pre-modern alchemical schemes such as Daniel Sennert's attempts at making gold by reducing metals to their primitive state (reductio in pristimum statum) in order to recover the potentials of matter to make all metals.
} 
alternative forms of life that could have been achieved by biological evolution. For instance, a research program named OUGEPO developed by a French geneticist (Philippe Marlière) and a mathematician (Philippe Bourguignon) systematically explores the horizons that natural selection discarded. The project is driven by the analogy with a surrealist literary game OULIPO designed by Raymond Queneau and Georges Perec. [35] It rests on the assumption that since current natural life is based on 20 molecules of amino acids while about 300 amino acids are used to make a protein, $20^{300}$ sequences are possible and consequently worth to be explored. While the discrimination between the physically possible and the technically feasible is the landmark of engineering work, the epistemological attitude developed in this project is exclusively concerned with the physically possible. It is aimed at unveiling potentials, regardless of their technological, ecological or ethical consequences.

The world becomes a field of potentials that need to be systematically explored because of the opportunities to play with. [36] Epistemic opportunism requires a mixture of imagination and reasoning but it easily generates techno-utopia as long as it is not concerned with the actualization of opportunities in the real world.

\subsection{Metaphysical perspective}

At the metaphysical level, the utopic dimension of novel forms of life is even more obvious. Unnatural nucleic acids would require unnatural amino acids, a new cell-machinery, and .... An entire world, parallel to the natural world, would have to be created for their actual existence. Indeed the notion of parallel worlds is logically possible. Leibniz's God, acting as a super-computer, was able to display all possible worlds. But knowing that they were not all physically com-possible, God decided to create only the best possible world. Unnatural biology ignores the condition of com-possibility. Although they occasionally claim to make better genetic material, synthetic biologists who craft exotic DNAs do not seem to be concerned with the actualization of the best possible form of life. They are content with the administration of "proofs of principle", demonstrating that other genetic codes, other cell machineries could exist, or have existed. They certainly legitimate novel forms of life as a preventing measure to avoid risks of contamination because alien genetic codes would not interfere or interact with natural ones. They would work independently from nature, in isolation. But what could be the mode of existence of isolated organisms?

Isolation, this seems to be the most prominent, and most problematic, feature of all artefacts designed in synthetic biology, not just in the unnatural biology branch. Biobricks are also designed as isolated functional artefacts made of synthetic, well-characterized units. They are supposed to perform well-controlled functions, independently from their environment, whatever the circumstances, overtime. As such they belong to the genre of utopia in a more literal sense. They exist in no-place (u-topia). They are both out-of-place, and out of time. The doubts - mentioned above in section 2.2 - about the possibility of securing permanent functionalities, and the recent evolution of metabolic engineering towards the integration of interactions between the synthetic system and the host cell, reveal the idealistic character of these foundational assumptions. Without entering into a detailed analysis of the ontological status of biosynthetic products, it is clear that these mixtures of nature and artefact are necessarily context-sensitive by their dual nature. [37] As technological objects they have to go through a process of "concretization". This term can be understood in two senses. In its common use it refers to the various steps leading from the abstract (theoretical principles, purposes and list of requirements) to the concrete (the finished product). In its more technical definition forged by the philosopher Gilbert Simondon, "concretization" is quite the contrary of the materialization of ideas or intentions. It refers to the process of convergence of functions in a structural unit and gradual inclusion of the environment in the operational 
scheme of the technical object. [38] Interestingly Simondon illustrated this notion with examples taken from the biological world. Biological objects are multifunctional and robust, not only because they are made of smart molecules but also because they are the outcome of evolution and genesis. Time is part of the stuff they are made of. Artefacts, just as natural objects are never permanent substances, they are rather processes. A fortiori, biotechnological objects, which combine genesis and poiesis, cannot exist out of time. What can be expected from organisms deprived of history? The question was raised by Lewis Mumford a few decades before the dawn of bioengineering and synthetic biology. [39] He condemned the chemists' ambitions of crafting viruses or bacteria in test-tubes as being i) redundant (why spend billion of dollars, thousands of hours and the elite of scientists for making micro-organism that can be found in abundance in oceans, in the air and everywhere?); ii) retrogressive (why moving three billion years backward and start making life from scratch?). These are certainly common-sense arguments. Nevertheless they are useful to highlight the reconfiguration of time initiated in synthetic biology. While the projects of making life de novo reverses the time arrow, the exploration of all possible forms of life breaks with the linearity of the time arrow and displays all possible forms of life in a space-like anisotropic dimension of time. In the latter configuration there is no future, just an eternal present of play with potentials.

Nevertheless, this out-of space, out-of time game may not be without impact on the real world. Even though the probability of interference between alternative genetic codes and the code of natural life is minimal, all biological systems are subject to mutations and natural selection. The novel forms of life will not escape the contingencies of evolution. Since all synthetic organisms will have to take place in the world, it is unrealistic to imagine that they will have a predictable behaviour. If they are capable of evolution they are not under human control.

In conclusion, the incredible promises characterizing the discourses about synthetic biology are not just rhetorical devices for attracting funds and creative young talents. They are integral part of the methods and expectations of the synthetic biology community. Between knowing and making, between understanding and constructing, synthetic biology develops a new vision of nature as a field of potentials to be explored for its affordances. Visions of the future are systematically engaged in dealing with the present for guiding action. However there are striking differences between the various branches of synthetic biology with respect to their balance between the possible and the actual. It seems that metabolic engineering and genomic engineering, whether driven by cognitive goals or by practical goals for making technological applications, put the emphasis on the actual. They seize all opportunities to construct real operational systems that can work as prototypes and shed new light on natural systems on the way. By contrast, the basic principles guiding the Biobrick program so much deny the complexity of living organisms that this movement can be characterized as a utopia, in the sense of using a fiction to change the world. The fiction of isolated modulus working independently can be compared to the "Cartesian novel" (the mechanistic vision of shaped and moved tiny particles making up the world), which deeply influenced the development of modern science. The branch of unnatural biology is more strictly speaking a utopia. In designing out-of-space and out-of-time forms of life, which are not adapted to any real context that we know, it forges an imaginary parallel world. It also captures the anticonformist flavour of all utopias since it intentionally subverts the order of nature. In this respect, it is closer to artistic creation than to traditional scientific investigation. Thus the tension between the possible and the actual provides a criterion for discriminating the various research agendas of synthetic biology. 


\section{References}

[1] David M. Berube (2006) Nano-Hype : The Truth Behind Nanotechnology Buzz, Prometheus Books, New York. Richard Jones (2008) Economy of promises, Nature Nanotechnology, 3: 65-66.

[2] Bensaude Vincent Bernadette (forthcoming) Discipline building in synthetic biology, In "Philosophical Perspectives on Synthetic Biology" Special Issue Studies in History and Philosophy of Biological and Biomedical Sciences (in print).

[3] Vinson V., Pennisi E. (2011) The Allure of Synthetic Biology, Science, 333 : 1235. [4] Nature, 436 (7067) 24 November 2005.

[5] Nature, 456, (7218) 6 November 2008.

[6] Carlson, Robert (2010) Biology is Technology: The Promise, Peril, and New Business of Engineering Life, Harvard University Press, Cambridge, MA,

[7] Austin J.L. (1962), How to do Things with Words: The William James Lectures delivered at Harvard University in 1955. Ed by J.O. Urmson Oxford: Clarendon.

[8] Nature Biotechnology, 22, N¹2, Dec 2009, 1071-1073.

[9] O'Malley MA, Powell A, Davies JF, Calvert J (2007) Knowledge-making distinctions in synthetic biology. BioEssays 30(1):57-65. Deplazes Anna (2009) « Piecing together a puzzle », Embo Reports 10, 2009, 428-432.

[10] Carlson Robert (2001) Biological Technology in 2050, The Economist, www.synthesis.cc/Biol_Tech_2050.pdf (accessed September 2012)

[11] Endy D (2005) Foundations for engineering biology. Nature, 438, 25 November: 449453.

[12] Paul C.W. Davies, Steven A. Benner, Carol E. Cleland, Charles H. Lineweaver, Christopher P. McKay, and Felisa Wolfe-Simon6 (2009) Hypothesis article: Signatures of a shadow biosphere, Astrobiology, 9, n², DOI: 10.1089/ast.2008.0251

[12] http://syntheticbiology.arc.nasa.gov/ (accessed September 2012)

[14] Steven A. Benner (2012), Redesign DNA: Fixing God's mistakes, The Pittcon Program 2012 Conference, Capstone, March 14, 2012, http://www.pittcon.org/technical/capstone.php (accessed September 2012)

[15] Philippe Marlière (2010), "Prométhée, Pandore et Pétri- Vie synthétique et OGM », http://www.vivagora.fr/index.php?option=com_content\&view=article\&id=1:prometheepandore-et-petri\&catid=16\&Itemid=114 (accessed September 2012)

[16] Editorial (2009) Unbottling the genes, Nature Biotechnology, 27, 12: 1059.

[17] Barbara Adam and Christopher Groves (2007) Future Matters, Action, Knowledge, Leiden, Brill.

[18] Henkel, J. \& Maurer, S.M. (2007): The economics of synthetic biology. Molecular Systems Biology 3 (117), 1-4. Rai, A. \& Boyle, J. (2007): Synthetic biology: caught between property rights, the public domain, and the commons. PLoS Comput Biol 5: 389-393.

[19] ETC Group (2007): Extreme Genetic Engineering. An Introduction to Synthetic Biology; http://www.etcgroup.org/en/materials/publications.html?pub_id=602 (accessed September 2012)

[20] Synthia is alive... and Breeding. Panacea or Pandora Box?

http://www.etcgroup.org/content/synthia-alive-\%E2\%80\%A6-and-breeding-panacea-orpandoras-box

[21] Schmidt, M., Kelle, A., Ganguli-Mitra, A., de Vriend, H. (eds., 2009): Synthetic Biology: The Technoscience and its Consequences, Dordrecht: Springer.

[22] Nordmann A.(2007) If and then. A critique of speculative ethics, Nanoethics, 1: 31-46. 
[23] Danchin Antoine (2008) Bacteria as computers making computers", FEMS Microbiology Reviews, 1-24 DOI:10.1111/j.1574-6976.2008.00137. Danchin A. (2009) Information of the chassis and information of the program in synthetic cells, Systems \& Synthetic Biology, [DOI $10.1007 / \mathrm{s} 11693-009-9036-5]$

[24] Antoine Danchin, (2012)Scaling up synthetic biology: Do not forget the chassis, FEBS Letters, http://pubget.com/paper/22226636

[25] O'Malley, M.A. (2009). Making knowledge in synthetic biology: Design meets kludge. Biological Theory, 4, 378-389.

[26] Elowitz M. B., \& Leibler, S. (2000). A Synthetic Oscillatory Network of Transcriptional Regulators. Nature, 403, 6767, 335-358.

[27] Nandagopal, N., \& Elowitz, M. B. (2011). Synthetic Biology: Integrated Gene Circuits. Science, 333, 1244-1248. See also Arkin A. (2008) Setting the standard in synthetic biology. Nature Biotechnoly 26(7):771-774.

[28] Knuuttila, T., \& Loettgers, A. (forthcoming). Basic science through engineering? Synthetic modeling and the idea of biology-inspired engineering, In "Philosophical Perspectives on Synthetic Biology" Special Issue Studies in History and Philosophy of Biological and Biomedical Sciences (in print)

[29] Steven Shapin (2007) What else is new?, The New Yorker, May 14, 2007, www.newyorker.com/arts/critics/books/.../070514crbo_books shapin (accessed September 24, 2012)

[30] Kirkham G. (2009) Is biotechnology a new alchemy?, Studies in History and Philosophy of Science, 40:70-80. Campos L. 2009. "That was the synthetic biology that was ", in Schmidt Markus, Agomoni-Kelle Alexander, Ganguli-Mitra, de Vriend Huib . Synthetic Biology: The Technoscience and its Consequences, Springer, Dordrecht, p. 5-21.

[31] Edgerton David (2008) The charge of technology, Nature, 22 October 2008, 455: 10301031 .

[32] Bensaude Vincent B. (2009)Synthetic biology as a replica of synthetic chemistry? Uses and misuses of history », Biological Theory 4(4) : 314-318.

[33] Hunyadi M. (2010), The imagination in charge, Nanoethics, 4:199-204

[34] Benner SA, Sismour AM (2005) « Synthetic biology », Nature Reviews Genetics 6, 533543.

[35] OUGEPO, ouvroir de génétique potentielle, http://www.ougepo.org/contact

[36] Nordmann, Alfred (2010) "Enhancing Material Nature“"In Kamilla Lein Kjølberg and

Fern Wickson (eds.) Nano meets Macro: Social Perspectives on Nanoscale Sciences and

Technologies, Singapur: Panstanford, 283-306.

[37] Kroes P, Meijers A (2006) The dual nature of technical artefacts. Studies in the History and Philosophy of Science A 37:1-4. Schyfter P. (2012) Technological biology ? Things and kinds in synthetic biology, Biology \& Philosophy, $27: 29$ - 48.

[38] Simondon G. (1958) Du Mode d'existence des objets techniques. Paris: Aubier, $2^{\text {nd }}$ ed. 1989. De Vries M.J. (2008) Gilbert Simondon and the dual nature of technical artifacts, Technê, 12 (1) : 1-15. [39] Mumford L. (1970) The Myth of the Machine. Vol II The Pentagon of Power, New York, Harcourt, Brace, Jovanovich. chapter 5. 